\title{
ТРАНСФОРМАЦИЯ ПРОЦЕССА ПРОИЗВОДСТВА ОБЩЕСТВЕННЫХ БЛАГ В УСЛОВИЯХ ЦИФРОВИЗАЦИИ
}

\author{
(C) 2020 Кравченко Антон Валерьевич
}

соискатель

Самарский государственный экономический университет, Россия, Самара

(c) 2020 Коновалова Мария Евгеньевна

доктор экономических наук, заведующий кафедрой экономической теории Самарский государственный экономический университет, Россия, Самара

E-mail: mkonoval@mail.ru

\section{(C) 2020 Кузьмина Ольга Юрьевна}

кандидат экономических наук, доцент кафедры экономической теории Самарский государственный экономический университет, Россия, Самара

E-mail: pisakina@yandex.ru

В статье проанализированы основные предпосылки трансформации процесса производства общественных благ в условиях становления и развития новой цифровой парадигмы. Показано, что ключевые проблемы предоставления общественных благ, такие как невыявленные предпочтения индивидов, «фрирайдерство», фискальная иллюзия, информационная асимметрия, могут быть решены посредством использования информационных технологий и цифровых платформ. Обоснован вывод, согласно которому в настоящее время наблюдается рост гибридных благ, в том числе имеющих цифровую природу, заключающий характеристики как частных, так и общественных товаров.

Ключевые слова: общественное благо, общественный сектор, проблема «безбилетника», индивидуальные предпочтения, мериторные блага, общественное благосостояние, асимметрия информации, цзифровизация, краудфандинг, краудсорсинг.

Общественное благо, как научная категория исследовалась многочисленными учеными в рамках различных направлений и школ экономической мысли, ключевое значение приобрели труды неоклассической школы, маржинализма, a, позднее, старого и нового институционализма. Несмотря на столь значительную степень разработанности проблемы производства и распределения общественных благ, она до сих пор остается дискуссионной, особенно в условиях трансформации традиционной парадигмы социально-экономического развития, обусловленного нарастающими процессами цифровизации [1]. Рост интерес к проблематике общественного сектора обусловлен, во-первых, неоднозначной ролью государственного вмешательства в функционирование экономической системы, во-вторых, постепенным размыванием границ между частными и общественными благами, нивелирующим институциональные рамки процесса производства опекаемых благ.

Как отмечает П.Самуэльсон, чистое общественное благо обладает двумя специфи- ческими свойствами: неисключаемости и неконкурентностью в потреблении. Еще одной характеристикой общественных благ является их неделимость, означающая, что индивид не может выбирать самостоятельно необходимый именно ему объем блага и не осуществляет оплату непосредственно за выбранное количество. П. Самуэлсон назвал их благами «которые все потребляют сообща в том смысле, что потребление такого блага каждым индивидом не ведет к сокращению такого потребления любым другим индивидом». Данные свойства общественного блага обусловливают отсутствие экономического интереса у частного капитала к их производству, следовательно, поставка опекаемых благ это прерогатива государства.

Специфически свойства общественных благ, представленные выше, детерминируют возникновение положительных внешних эффектов за счет того, что издержки производства общественного блага не зависят от количества его потребителей. Поэтому основной задачей государства является определение оптимального 
объема предоставления общественного блага. В экономической науке учеными достаточно глубоко исследовался данный вопрос, существует доставочное количество предложенных моделей и механизмов выявления необходимого объема производства общественных благ. Так, в модели добровольного обмена Э.Линдаля представлена идеальная ситуация соглашения двух индивидов, совместно осуществляющих производство общественного блага. Предполагается, что индивиды могут достичь соглашения относительно вклада каждого из участников, который достигнет оптимального значения и позволит произвести общественное благо в необходимом объеме. Критики данной модели указывают, что равновесие по Линдалю показывает лишь один из вариантов Парето-оптимального состояния системы и распределения ресурсов. Между тем существует множество таких вариантов, и не факт, что будет выбран наилучший. Нереалистичность модели Линдаля обусловливает необходимость осуществления государственных мер по производству и финансированию общественных благ, необходимым элементом которых является механизм инфорсмента.

Еще одним механизмом, регламентирующим процесс производства общественных благ, является налог Кларка [2], суть которого состоит в том, что обман и искажение информации становится не выгодным индивидам. Налог Кларка для конкретного жителя равен изменению благосостояния остальных жителей, которое произошло бы, если бы данный индивид не принимал участие в голосовании по проблеме принятия решений о производстве конкретного общественного блага. Помимо налога Кларка каждый индивид платит налог, равный стоимости общественного блага, деленной на число жителей, и он не зависит от предпочтений индивидов и объема потребления ими опекаемого блага. Несмотря на понятную схему установления налога Кларка, данная мера не всегда приводит к цели, то есть с помощью этой меры все-таки не удается выявить истинные предпочтения субъектов. Теория общественного выбора демонстрирует другой подход к решению проблемы выявления индивидуальных предпочтений субъектов и определения оптимального объема производства опекаемых благ. Речь идет о механизмах принятия коллективного решения посредством политического процесса в его разнообразных формах. Общественный выбор представляет собой коллективную выработку решений относительно общественных благ и перераспределения. Коллективные речения принимаются не только через структуры государства, они являются условиями любой добровольной совместной деятельности, поэтому коллективный выбор достаточно широкое понятие [3]. В отличие от частных благ спрос на которые определяется в процессе рыночного обмена, потребности в общественных благах могут определяться только в процессе коллективного выбора с помощью политических институтов демократии. Механизм общественного выбора имеет ряд отличий по сравнению с рыночным механизмом индивидуального выбора. Во-первых, рыночное взаимодействие не требует намеренного согласования позиций, а коллективный выбор предполагает сознательно принятие процедуры, в рамках которой заявляются индивидуальные предпочтения и на основе их сопоставления определяется совместное решение, то есть процедуры голосования. Во-вторых, рыночное взаимодействие всегда приводит Парето-улучшениям, а коллективное решение, если оно принимается не единогласно, может порождать ущерб для тех, кто остается в меньшинстве. В-третьих, индивид, приобретающий товар на рынке безразличен к предпочтениями других покупателей, в случае коллективного выбора каждый участник заинтересован в том, чтобы предпочтения других лиц совпали с его собственными. Чем ближе друг к друг индивидуальные предпочтения, тем легче их согласовать. В-четвертых, функционирование рыночной системы базируется на гарантиях экономической свободы, в то время как механизм общественного выбора предполагает принудительный порядок финансовых взаимоотношений государства и его членов. В-пятых, на рынке система свободных цен играет роль регулятора экономического поведения, тогда как механизм общественного выбора включает структуры государственного управления, то есть бюрократический аппарат. В рамках теории общественного выбора и принятия коллективных решений сформировалась несколько представлений об оптимальной процедуре голосования. Наиболее известными из которых является правило большинства и, как следствие, парадокс Кондорсе, а также теорема о невозможности K. Эрроу [4]. Еще в XVIII веке маркиз де Кондорсе выявил парадокс, состоящий в том, что правило простого большинства не гарантирует транзи- 
тивности коллективного выбора, а значит, его нельзя признать рациональным. Известный экономист К.Эрроу сформулировал теорему о невозможности, которая утверждает, что не существует правила коллективного выбора, удовлетворяющее одновременно следующих условиям: полнота, универсальность, транзитивность, единогласие, независимость от посторонних альтернатив, а также отсутствие диктатуры. Теорема о невозможности подчеркивает, что действенность политического процесса и институтов власти зависит от степени противоречивости интересов, представленных в обществе. Коллективный выбор в условиях демократии успешнее всего осуществляется при наличии таких профилей предпочтений, которые в конечном счете отражают консенсус по базовым ценностям. При наличии непримиримых противоречий любые процедуры голосования могут давать неоднозначные результаты. Дальнейшие исследования определения предпочтений индивидов посредством политического процесса осуществлялись в трудах Д.Блэка, предложившего модель медианного избирателя, суть которой состоит в том, что если индивидуальные предпочтения являются одновершинными, то устойчивую коллективную поддержку получает альтернатива, наиболее предпочитаемая медианным избирателей [5].

В настоящее время в условия формирования цифровой парадигмы социальноэкономического развития проблемы выявления предпочтений индивидов приобретает несколько иной ракурс. Проникновение цифровых технологий в различные сферы социальноэкономической деятельности способствует росту производительности и поддерживает всесторонне развитие [6]. Использование цифровых технологий повышает рентабельность капитала, производительность труда, что позволяет участвовать в глобальных цепочках создания добавленной стоимости. Внедрение цифровых технологий обусловливает формирование условий для создания общественных товаров на новой информационной основе. Появляются новые виды общественных благ, обладающих сетевых эффектом. Такие блага не имеют аналогового формата и предстают исключительно в цифровом виде, например, социальные сети [7,8]. Особенностью данного вида благ являются то, что издержки на их производство незначительны, поскольку оригинал единицы блага нисколь- ко не отличается от ее копии, то есть тиражирование объема не вызывает роста затрат. Следует подчеркнуть, что сетевые блага, создаваемые исключительно в цифровом формате обладают свойствами общественного блага, неисключаемостью и несоперничеством. Потребление такого блага одним индивидом не уменьшает его количества, доступного для потребления другим субъектом.

Возможность создания цифровых благ посредством использования информационных технологий обусловливает трансформацию роли государства как традиционного поставщика общественных благ. В экономической литературе появляются публикации, посвященные формированию предпосылок для добровольного объединения граждан для поставки общественного блага. Проникновение сети интернет во все сферы жизнедеятельности общества меняет способ координации хозяйствующих субъектов, в обществе начинают превалировать горизонтальные связи, субъекты могут объединятся для достижения поставленных целей без вмешательства государства или подобного рода посредника на добровольной основе [9]. Значительное влияние на возможность совместного производства общественного блага оказывает прошлый положительный опыт, позитивные результаты партнёрства, что обусловливает укрепление доверия между индивидами. Рост персонифицированного и неперсонифицированного доверия обусловливает возможность производства общественного блага и его совместного потребления субъектами. В научном сообществе все чаще появляются дискуссии относительно развития так называемой sharing economy, экономики совместного потребления или долевой экономики, как ее иногда называют [10]. В начале двадцатого века в связи с интенсивным распространением Интернета стало возможным появление новых форм рыночного обмена между незнакомыми людьми. Экспансия цифровых технологий, распространение сетевых эффектов [11] делает возможным объединение граждан в сообщества, оформление которых происходит в рамках микросоциальных контактов. Основной социально-экономический эффект от шеринг-экономики состоит в потенциально более справедливом распределении благ, росте общественного благосостояния, а также с позитивными экологическими экстерналиями обусловленными снижением объема материального производства. 


\section{Библиографический список}

1. Mikhailov A. M. Kopylova A. A. // Relationship Between the Economy Digitalization and the «Knowledge» Production Factor // Lecture Notes in Networks and Systems (см. в книгах). 2020. Т. 84. С. 27-38

2. Clarke E. H. Multi-part pricing of public goods // Public Choice.1971.Vol.11. P. 17-33.

3. Вольский В.И. Ж .-Ш. де Борда и маркиз де Кондорсе - родоначальники теории голосования// Полития. № 3 (70). 2013.- С. 147

4. Kenneth J. Arrow. Social Choice and Individual Values, Yale University Press,2012. P.192

5. Condorcet $M$. de Essai sur 1, applications de 1, analuse a la probability desdecisions rendues a la plurulite des voix. Paris, 1755. P.54.

6. Ролз Дж. Теория справедливости. Новосибирск: Изд-во НГУ, 1995. С. 345

7. Бъюкенен Дж. М. Сочинения. Пер.с англ. Серия: «Нобелевские лауреаты по экономике». Т.1./ Фонд экономической инициативы; Гл. ред. Ко.: Нуреев Р. М. и др./ - М.: «Таурус Альфа», 1997. С.54-59

8. Кастельс М. Становление общества сетевых структур.-М.2003.-С. 494.

9. Дятлов С.А. Цифровая нейро-сетевая экономика: институты и технологии развития: монография / С. А. Дятлов, О.С. лобанов, Д. В. Гильманов.-СПб.: Изд-во СПбГЭУ, 2018.- С.12.

10. Вахитова Л.Р., Кудрявцева К. В. Переосмысление понятия общественных благ в цифровую эпоху // научный журнал НИУ ИТМО. Серия Экономика и экологический менеджмент. № 2. 2020. С. 216.

11. Коновалова М.Е., Михайлов А. М., Кузьмина О.Ю. Прогнозирование развития фондовых рынков в условиях становления цифровой экономики // Вестник Самарского экономического университета. 2018. № 11 (169). С.13-19. 